\title{
How Government Regulations and Consumer Behavior Influence Manufacturers' Product Green Degree Decision-Making: An Agent-Based Model
}

\author{
Pengwei Yuan $\mathbb{D}$, ${ }^{1}$ Xiaoqing Dong $\mathbb{D}^{1},{ }^{1}$ Jia $X u\left(\mathbb{D},{ }^{2}\right.$ and Xiaofei Lin $\mathbb{D}^{3}$ \\ ${ }^{1}$ School of Business, University of Jinan, Jinan, 250022 Shandong, China \\ ${ }^{2}$ School of Urban Rail Transportation, Shanghai University of Engineering Science, Shanghai 201700, China \\ ${ }^{3}$ Civil Engineering and Agriculture School, Anhui University of Technology, Maanshan, 243032 Anhui, China \\ Correspondence should be addressed to Xiaoqing Dong; sm_dongxq@ujn.edu.cn
}

Received 28 January 2021; Revised 24 March 2021; Accepted 22 April 2021; Published 13 May 2021

Academic Editor: Wenqing Wu

Copyright ( $) 2021$ Pengwei Yuan et al. This is an open access article distributed under the Creative Commons Attribution License, which permits unrestricted use, distribution, and reproduction in any medium, provided the original work is properly cited.

\begin{abstract}
In recent years, green product issues have received increasing attention. Both government regulations and consumer behaviors have a strong influence on the product green degree decisions of manufacturers' products. In order to find how government regulations and individual's green product purchase behavior affect manufacturers' green degree decisions and the market evolution characteristics, this paper proposes a multiagent model that considers the interaction among government, consumers, and manufacturers. The simulation results show that, firstly, the product green degree decision-making of manufacturers needs the guidance and regulation of the government. Secondly, product price subsidies are the most effective way to affect the manufacturers' product green degree decisions. In contrast to giving green cost subsidies to manufacturers, the government employs various publicity means to improve the environmental awareness of consumers is also an effective way to enhance the green degree of manufacturers' products. Thirdly, there is a "Crowding Out Effect" on the other qualities of manufacturers' products when manufacturers focus on the green degree of their products.
\end{abstract}

\section{Introduction}

As the global economy develops and the population increases, the consumption of natural resources around the world is growing at a high-speed rate $[1,2]$. In consequence, air pollution, water pollution, and other environmental problems are becoming extremely serious [3]. The production and consumption of green products are becoming the consensus of all countries in the world [4]. Consequently, manufacturers are motivated and encouraged to produce green products by government $[1,5,6]$. The concept of product green degree, which indicates the environmental friendliness of the product, was used to identify nongreen products and competitive products [7]. Consumers in the market have different demands for the green degree of products [8]. In order to better meet the requirements of government and consumers, manufacturers have to consider an appropriate green degree of products to enhance market competitiveness. So, what level of green degree is both popular with consumers and profitable for a manufacturer? It is a question worth looking into.

There are three main stakeholders related to the green degree decision-making of products, namely, manufacturers, consumers, and government [9]. As the supplier of green products, manufacturers need to weigh various factors when making decisions on the green degree of products to adapt to the fierce market competition. First of all, manufacturers have to clearly understand their resources, such as the green degree of products, market share, profits, and whether there are extra resources and capabilities to enhance their products' green degree [10]. Secondly, the profitability of a manufacturer is closely related to its competitors [11, 12]. Therefore, manufacturers often need to consider the situation of their competitors when deciding on the green degree of products, with the aim of learning and surpassing them. As the demander of green products, consumers' preference for 
the green degree of products directly affects the decisionmaking behavior of manufacturers [9]. Consumers' purchasing behaviors are influenced not only by the product's characteristics (such as price and quality) $[5,6]$ but also by the people around them [13]. In recent years, with the development of mobile Internet, the prosperity of social media represented by Twitter and microblog provides a more convenient and efficient platform for the spread of word-of-mouth products. A growing number of people are willing to buy products recommended by others on social media, which shows that more and more people recognize the shopping information and have trust in this information on social media [14]. Thus, we put consumers' mutual learning behavior in online social network into the purchase decision model in this study.

Besides, the price of green products is usually higher than that of ordinary products, which will reduce consumers' purchase desire to some degree [15]. Therefore, the government needs to take corresponding measures to stimulate green product consumption, and of course, it also needs the government to formulate related environmental standards and punishment measures to restrain manufacturers [16], which are all aimed at reducing carbon emissions and protecting the environment. Therefore, the interactions of manufacture, consumers, and the government make the decision-making of product green degree very complicated. And the evolutionary mechanism of manufacturers' green decisionmaking is unclear. Therefore, we find that the following problems are worth to in depth study: How does the manufacturer make decisions of products' green degree under government regulation? How does the manufacturer make decisions of products' green degree in the face of consumers' demand, preference, and interaction? What are the evolutionary tendencies of green products in the market for manufacturer groups under different scenarios?

To solve these three problems, we use the agent-based modeling approach to study the mechanism of manufacturers' green degree decisions and analyze the trend of the evolving choices of manufacturers with different green degrees, which is rare in the study of manufacturers' green decision problems. These are very important for clarifying the macro behavior mechanism of manufacturers' green degree decision and the market evolution characteristics of green products in different situations. The originalities and features of this work are described below. Firstly, this work focuses on the influences and interactions among consumers, manufacturers, and government on the micro green degree decision of manufacture, which is different from the previous studies concentrating on the relationship between manufacturers and government or manufacturers and consumers. Secondly, apart from considering the impact of a product's multiple attributes (price, green degree, quality, etc.), this work also considers the characteristics of agent purchasing behavior, like the customers' purchasing power, their environmental preference differentiation, the influence of interaction on customers' purchase decisions in online social networks, the government's subsidies and penalties, and the competition and learning behaviors among manufacturers. Consequently, the model we develop in this work is closer to the real market. Thirdly, this study gives an observable evolution of the product's green degree in different scenarios like different consumers' environmental awareness and analyzes various market indicators such as the average product green degree, average product green degree, and average manufacturer profits.

\section{Literature Review}

2.1. Manufacture's Decisions on Green Product. The studies of manufacture's decision on green products could be classified into two aspects: the influence of market and consumer attributes and how to decide in the supply chain environment. On the subject of the market and consumer attributes, Liu et al. [17] analyzed the impacts of competition and consumers' environmental awareness on the profiting ability of manufacturers having various eco-friendly products. Swami and Shah [18] indicated that manufacturers' and retailers' green efforts result in increased market demand, and their optimal green efforts depend on their green sensitivity and green costs. Nouira et al. [19] suggested that when a company faces a market with both regular and green customers, offering different types of products to each market segment can significantly increase the company's profits. Moser [20] suggested that companies need to maintain a specific pricing strategy as well as conduct appropriate promotions to promote the benefits of green products to consumers. Chen and Sheu [21] analyzed the impact of market uncertainty and consumer rationality on firms' green strategies and found that it is not always advantageous to adopt a differentiation strategy to produce products with different green degrees; in some cases, it is more beneficial for firms to adopt a follow strategy to produce products with the same green degree as their competitors. Hong et al. [22] studied the green product pricing problem by considering consumers' environmental awareness and the reference of non-green products and found that firms should adopt different pricing strategies based on their green production costs in an asymmetric information scenario. Du et al. $[5,6]$ found that traditional enterprises tend to reduce the price of products in order to maintain market share, resulting in green products only sold to some green consumers in the competitive environment. Li et al. $[11,12]$ showed that the product green degree of manufacturers shows a "convergence" effect if manufacturers learn the benchmark manufacture that gets the best profits in the market.

With reference to how to make decisions on green products in a supply chain environment, Ghosh and Shah [23] studied that how greening levels, prices, and profits of green apparels supply chain are influenced by channel structures, greening costs, and consumer sensitivity. Xie [24] studied the Chinese automobile supply chain and found the market competition intensity has an impact on the energy-saving level of green products. Li et al. [11, 12] revealed that the revenue-sharing contract and cost-sharing contract between manufacturers and retailers have different effects on emission reduction efforts and corporate profitability. Yang and Xiao [25] investigated the way in which prices, greenness, and expected profits of green supply chains are influenced by the channel leadership and government subsidies in an 
environment where production costs and consumer demand are ambiguous. Shen et al. [26] discussed the product lines of supply chain and product quality for green and nongreen products. They found that improving product quality can enhance consumer welfare and lessen environmental impact. Saha et al. [27] discussed the important role of intermediaries in coordinating green supply chains under price and green level sensitive demand. Fang et al. [28] investigated price and order strategies for innovative green products using demand forecasting and sharing. Xin et al. [29] studied the problem of coordinating two levels of green product supply chains in the presence of uncertain demand from environmentally conscious consumers and found that two-part tariff contracts can always coordinate the supply chain. Zhang et al. [30] found that if manufacturers distributed brown and green products separately through different retailers, they could achieve higher profits through strategic pricing without changing their product portfolios.

\subsection{Consumers' Green Product Purchasing Behavior. Con-} sumers' green product purchasing behaviors have mainly been studied in consumer demands, preferences, purchasing power, etc. Olson [31] found that because green products usually have higher prices and lower quality, consumers tend to buy products with lower green degrees. Zhao et al. [32] found that consumer attitude is the most critical indicator to predict consumers' green purchasing behavior. When consumers' attitude is more positive, and they pay more attention to the environment, consumers are more likely to buy green products. Du et al. $[5,6]$ suggested that consumers with green preferences are willing to pay higher prices for products with low-carbon emissions. Yadav and Pathak [33] found that the green purchasing behavior of young Indian consumers can be predicted by their attitudes, subjective norms, and environmental concerns. Suki [34] revealed that consumers' knowledge of green brands is the most critical factor in the formation of their green purchase intention, and green brand knowledge can effectively enhance consumers' green awareness and promote their purchase of green products. Zhu et al. [35] found that the purchasing power of consumers' families often determines whether the consumers' purchase intention of green food can be transformed into real green food purchasing behavior. Yang and Zhao [36] analyzed 526 Chinese consumers about their purchase behavior of household energy-saving and renewable energy equipment. They found that consumer purchasing power had a positive moderating effect on the relationship between equipment purchase attitude and behavior intention. Jo and Shin [37] showed that age and purchasing power would evidently influence consumers' preference for green product attributes. Kowalska-Pyzalska [38] revealed that the willingness of Polish residents to pay for renewable energy was positively correlated with their purchasing power and education.

In addition, many studies have identified consumer interaction as an important factor in influencing consumer purchases of green products. Lin et al. [39] built a consumer choice model by adding social influence attributes. They took hybrid electric vehicles as an instance to explore the impact of consumer interaction networks on the promotion of hybrid charged vehicles. McCoy and Lyons [40] found that although the overall purchase rate of electric cars is low, the slight peer effect brought by the network will promote consumers to purchase actively and form a higher purchase rate in some regions. Khare [41] found that peer influence, previous green purchasing behavior, and green self-identity enhance Indian consumers' purchase intention of green products. Using green hotels as an example, Wang et al. [13] showed that the green image of a green product strongly influences consumers' green satisfaction and green trust, which in turn positively drives word-of-mouth interactions in order to recommend the product to other consumers. Chen et al. [42] used empirical research on the green purchasing behavior of consumers in the "Belt and Road" country and showed that consumer interactions have a positive influence on consumers' green purchasing behavior.

2.3. The Influence of Government Regulation on Green Product Decision. The Porter hypothesis first proposed that environmental supervision can promote green innovation in manufacturers under appropriate conditions [43]. In recent years, many scholars have shown that government environmental regulation can provide incentives for manufacturers to carry out green innovation when they do not choose to do so themselves. Sheu and Chen [44] suggested that the government should adopt taxation and subsidy policies to ensure that the green profits from the production of green products by firms are nonnegative. van Leeuwen and Mohnen [45] demonstrate the positive impact of environmental regulation on corporate green innovation through an empirical study of Dutch manufacturing firms. Wang et al. [46] compared and analyzed the incentive effects of different subsidy policies, such as product subsidies and R\&D subsidies, in different stages of green efforts in the remanufacturing industry. Madani et al. [47] pointed out that an increase in government subsidy rates will lead to increased product green degree, supply chain profits, and government revenues, which will be better than an increase in tax rates. Yang et al. [25] found that in an ambiguous environment, the green degree of products increases when government subsidies rise, but government subsidies do not always favor the green supply chains and can even lead to action disadvantages for first movers. Huang et al. [48] analyzed the influence of green loan size and government's green subsidies on enterprise green innovation, and they confirmed the effectiveness of government subsidies in facilitating green innovation and environmental sustainability. Saha et al. [27] discussed the impact of government subsidies to consumers and subsidies to manufacturers on supply chain profits from the perspective of supply chain cooperation contracts. Nielsen et al. $[49,50]$ studied the impacts of government's perunit product cost subsidies and $\mathrm{R} \& \mathrm{D}$ investment subsidies on supply chain members under different circumstances. $\mathrm{Xu}$ et al. [51] found that government regulations can promote green decision-making behavior, and the regulations on manufacturers are more effective than those on suppliers.

To sum up, the existing literature has conducted a lot of studies on the manufacture's decision on green products, 
which has laid a good foundation for this paper. However, most of the studies focus on the decision problems in a single enterprise or a single supply chain under the influence of different factors and less on the group behavior of green product decisions. In fact, when manufacturers are competing in the market, they are not only influenced by partners in the supply chain, but also by their competitors in the market. Furthermore, consumers' green purchasing behavior is not only related to their characteristics but also influenced by their interactions. In fact, consumers are in social networks, and their purchasing behavior will be affected by other consumers in the social network. So, the market demand of consumers cannot be portrayed as a result of a linear function of attributes such as product price and quality. Finally, facing the interaction between manufacturers and consumers, the influence of consumer interactions, imitation, and learning among manufacturers, how the government implements their regulatory measures to improve the green degree of products in the market as a whole has not been well explained.

\section{Agent-Based Modeling}

3.1. The System Design. Manufacturers, customers, and the government make up the market system. And it is a complex adaptive system with the characteristics of complex, dynamic, and nonlinear. In this study, we used an agentbased modeling method to build our model. ABM can clarify the evolution law of the nonlinear behavior of the complex system in the real world by setting interaction rules of agents [52]. Agent-based models are widely used to model dynamical behaviors of systems in a variety of fields, such as economics, social science, organizational science, behavioral ecology, and physics [53].

Our goal is to find how government regulation and individuals' green product purchasing behavior affect manufacturers' green degree decision and market evolution characteristics. Therefore, we developed an ABM simulation model of the green product market, which including government, consumers, and manufacturers. The government, consumers, and manufacturers are connected through products in the market. A schematic illustration of agents' decisionmaking and interaction mechanism is shown in Figure 1.

As shown in Figure 1, in order to increase environmental benefits and reduce pollution, the government will set green standards for products and subsidize the manufacturers and consumers who produce and purchase corresponding green products and punish enterprises that are lower than the related standards. The consumer agents in the model are connected to each other through social links. The social links connect one consumer to another works as a channel that can transmit information and knowledge of products. In the process of market transactions, consumers will make purchase decisions that are affected by one's purchasing power, the expectation and sensitivity of the product's price, quality, etc. Besides, communications among consumers like recommendations, criticism, and complaints, can influence consumers' purchase decisions, and it may create a herd effect during the interaction. In the process of market transactions, manufacturers will modify the product green degree and other quality on the basis of competitors' information nearby and their own historical experience.

3.2. The Government Agent. The government implements some interventions for social welfare $[2,54]$. It is supposed that the government sets a product green degree standard $g_{l}$ for the manufacturers' product to enter the market. The government dynamically supervises the manufacturer by the mean of random sampling according to the probability $\theta(0 \leq \theta \leq 1)$. Then, if the green degree $g_{j}$ of manufacturer $j$ 's product fails to meet the standard $g_{l}\left(g_{j}<g_{l}\right)$, the government will punish the manufacturer in the form of a fine, which is related to the green degree of the products. The lower the products' green degree $g_{j}$ is, the greater the punishment is. It is assumed that $\mathrm{sm}_{j}=1$ denotes the manufacturer $j$ is sampled; otherwise, $\mathrm{sm}_{j}=0$. The punishment function $\mathrm{PF}_{j}$ is defined as follows:

$$
\mathrm{PF}_{j}= \begin{cases}\rho\left(g_{l}-g_{j}\right) & \text { if } \mathrm{sm}_{j}=1 \text { and } g_{j}<g_{l} \\ 0 & \text { if } \mathrm{sm}_{j}=1 \text { and } g_{j} \geq g_{l} \\ 0 & \text { if } \mathrm{sm}_{j}=0,\end{cases}
$$

where $\rho$ is the penalty coefficient and $\rho>0$.

Similarly, it is assumed that the government develops the product green degree standard $g_{h}$ of product, and the manufacturer can apply for subsidies of product's cost when its product is higher than the standard $g_{h}$. The subsidy function is as follows:

$$
\mathrm{SF}_{j}= \begin{cases}\frac{1}{2} \alpha u_{j}\left(g_{j}-g_{h}\right)^{2} & \text { if } g_{j} \geq g_{h}, \\ 0 & \text { if } g_{j} \leq g_{h},\end{cases}
$$

where $u_{j}$ represents the cost factor associating with the green degree $g_{j}$, and $\alpha(0<\alpha<1)$ denotes the subsidy proportion of the green production cost of manufacturer $j$.

Moreover, the price subsidy is an effective means for the government to guide consumers to buy green products [55]. It is supposed that $p_{s j}$ denotes the subsidy for green product of manufacturer $j$ whose green degree is higher than the specified standard $g_{h}$; and it can be expressed as follows:

$$
p_{s j}= \begin{cases}p_{j} \gamma\left(g_{j}-g_{h}\right) & \text { if } g_{j} \geq g_{s}, \\ 0 & \text { if } g_{j} \leq g_{s} .\end{cases}
$$

\subsection{Consumer Agents}

3.3.1. Consumers' Social Network. Consumers' social networks in the real world are different from those formed by Internet users [56]. Many empirical analyses show that social networks in the real world are mainly represented by smallworld networks, and most of the social networks in the internet world are scale-free networks $[40,57]$. In recent years, 


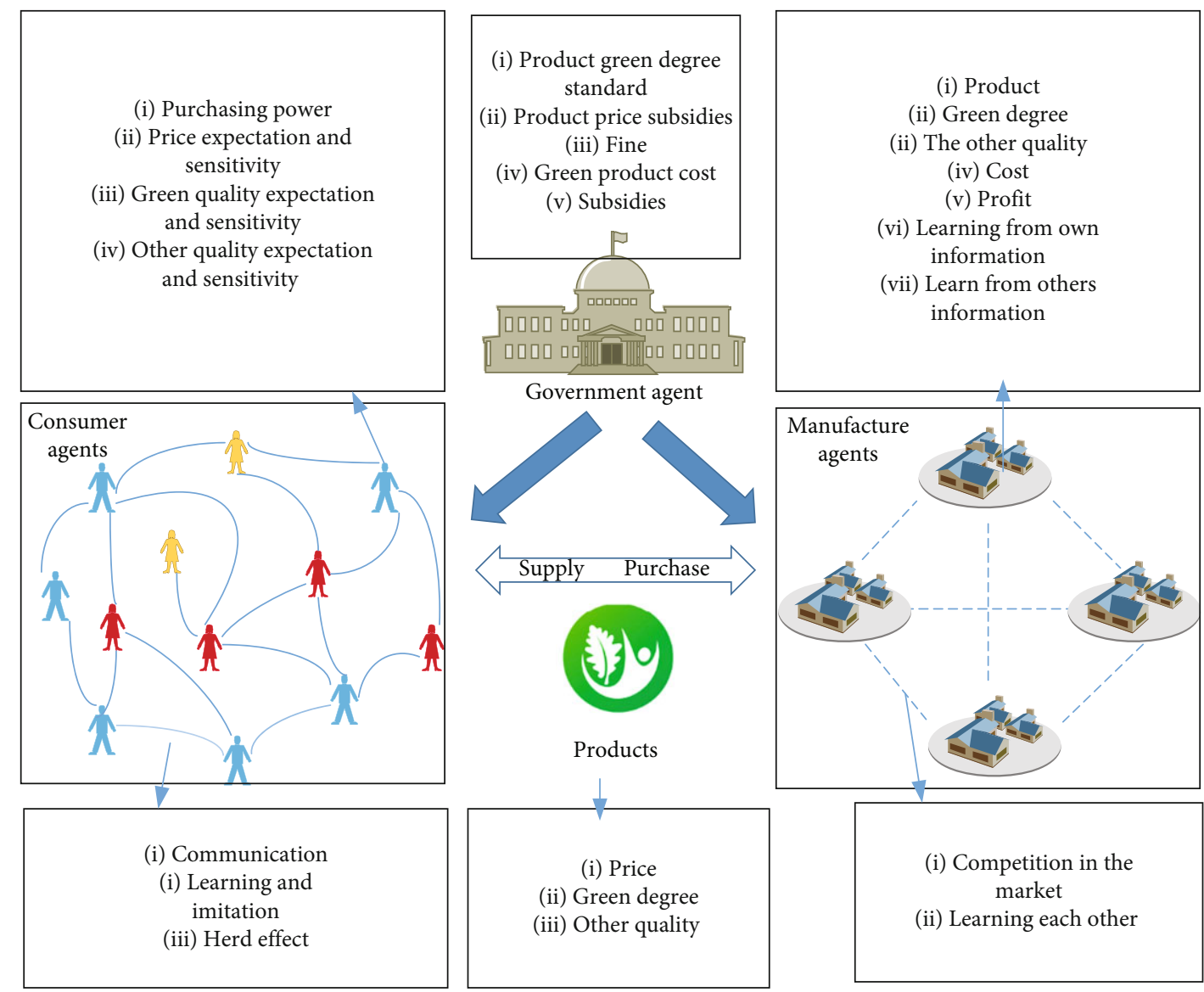

Figure 1: Agents' decision and interaction mechanism.

with the popularity of online social platforms, more and more consumers spontaneously share product purchase experience and evaluation information on social media (like Twitter, Weibo, and WeChat), so we use a scale-free network to describe the network relationship of consumers. The scalefree network refers to the network whose node degree satisfies "power law distribution", and it can describe both the small-world property and large variations of node degrees in a network [58]. In a scale-free network, most "ordinary" nodes have few connections, while a few "hot" nodes have extremely many connections. The scale-free network starts from $m_{0}$ nodes ( $m_{0}$ is a positive integer), which are connected, and each evolution produces a new node. The probability of the new node connecting with the original nodes is directly proportional to the degree of the original nodes and finally evolves into the state that the degree distribution does not change with the network size and obeys the power-law distribution [58].

3.3.2. Consumer Choice Behavior. It is assumed that a consumer only makes one purchase decision and only chooses one product of a manufacturer in a simulation tick. The comprehensive utility function of consumers is developed on the ground of the information collected on the product and the interactions with his friends in the social network. According to the researches of Zhang T. and Zhang D. [59] and Čavoški and Marković [60], we can formulate the function as follows:

$$
U_{i j}=C_{i j} \times p_{j}+\beta_{i} \times G_{i j} \times g_{j}+Q_{i j} \times q_{j}+\mathrm{FE}_{\mathrm{ij}},
$$

where $U_{i j}$ is the utility that consumer $i(i=1$ to $M)$ purchases a product of manufacturer $j(j=1$ to $N) ; C_{i j}$ is a consumer agent assessing the $j$-th manufacturer's price, and $P_{j}$ is the price of manufacturer $j$ 's product; $G_{i j}$ is the effect of $j$ -th manufacturer's green degree on consumer agent $i, g_{j}$ is $j$-th manufacturer's green degree, and $\beta_{i}\left(0<\beta_{i}<1\right)$ denotes the consumer agent's green preference and environmental awareness; $Q_{i j}$ is other quality utility (like perform and life) except green degree, and $q_{j}$ is the product other quality of manufacturer $j ; \mathrm{FE}_{i j}$ reflect the "WOM" effect of the consumer agent following his friends' opinion about manufacturer $j$ 's products in the social network.

The coefficient $C_{i j}$ expresses the effect of manufacturer's price on consumer agent's attitude to purchasing the product of manufacturer $j$. In general, a higher price tends to reduce the consumers' purchasing motivation of the product. Kim et al.'s research suggested that the lower price a product is, the less sensitivity of the consumer towards the product is [61]. So, sensitivity to price can be expressed as follows:

$$
C_{i j}=-\varepsilon_{i}^{p_{j}-p_{s j}-p_{e}},
$$


TABLE 1: The parameters and variables' initial value in the model.

\begin{tabular}{|c|c|c|c|}
\hline Parameters & Explanation & Range & Distribution \\
\hline$M$ & Number of consumers & 30,000 & Constant \\
\hline$N$ & Number of manufacturers & 40 & Constant \\
\hline$g_{j}$ & Green degree of manufacturer $j$ 's product & {$[0,100]$} & $\begin{array}{l}\text { The initial value follows a uniform } \\
\text { distribution }\end{array}$ \\
\hline$g_{l}$ & Standard for manufacturers' product entering the market. & 30 & Constant \\
\hline$g_{h}$ & Green degree requirement for subsidy application & 70 & Constant \\
\hline$\theta$ & Government sampling rate & 0.3 & Constant \\
\hline$\rho$ & Government's penalty coefficient & 2000 & Constant \\
\hline$\alpha$ & Government's cost subsidy coefficient & 0.5 & Constant \\
\hline$\gamma$ & Government's price subsidy coefficient & 0.08 & Constant \\
\hline$q_{j}$ & The other quality of manufacturer $j$ 's product & {$[20,100]$} & $\begin{array}{l}\text { The initial value follows a uniform } \\
\text { distribution }\end{array}$ \\
\hline$\beta_{i}$ & Environmental awareness & {$[0.5,2]$} & Uniform distribution \\
\hline$\varepsilon_{i}$ & Consumer's price-sensitive parameters & {$[1,20]$} & Uniform distribution \\
\hline$\delta_{i}$ & Consumer's green degree sensitive parameters & {$[0.4,0.6]$} & Uniform distribution \\
\hline$\tau_{i}$ & Consumer's other quality sensitive parameters & {$[0.4,0.6]$} & Uniform distribution \\
\hline$k_{i}$ & Consumer's purchasing power & $\begin{array}{c}N(55, \\
15)\end{array}$ & Normal distribution \\
\hline$a_{1}, a_{2}$ & Regression coefficient of purchasing power & 0.75 & Constant \\
\hline$a_{3}, a_{4}$ & $\begin{array}{c}\text { Consumers' cost coefficient of product green degree and the other } \\
\text { quality }\end{array}$ & 1.5 & Constant \\
\hline$b_{1}, b_{2}$ & $\begin{array}{c}\text { Consumer's fixed expectation of product green degree and the other } \\
\text { quality }\end{array}$ & -13.54 & Constant \\
\hline$f_{i}$ & Consumer's sensitivity parameter to his friends' influence & $(0,1.5)$ & Uniform distribution \\
\hline$c_{j}$ & Regular unit cost of manufacture & {$[3,10]$} & Uniform distribution \\
\hline$u_{j}$ & The cost coefficient associating with the green degree $g_{j}$ & 0.03 & Constant \\
\hline$z_{j}$ & The cost coefficient associating with the other quality & 0.03 & Constant \\
\hline$e_{j}$ & Manufacture's profit margins & {$[0.1,0.3]$} & Uniform distribution \\
\hline$v$ & Random number & {$[0,1]$} & Uniform distribution \\
\hline lea1 $1_{j}$ & Manufacture’s leaning ability of green degree & {$[0.1,0.5]$} & Uniform distribution \\
\hline lea $2_{j}$ & Manufacture's leaning ability of the other quality & {$[0.1,0.5]$} & Uniform distribution \\
\hline$d$ & Distance threshold & 15 & Constant \\
\hline
\end{tabular}

TABLE 2: The parameters' change of different scenarios.

\begin{tabular}{lc}
\hline Scenarios & Parameters change \\
\hline Scenario 1 & $\theta=0.3, \rho=2000, \alpha=0.5, \gamma=0.08 \longrightarrow s=0, \rho=0, \alpha=0, \gamma=0$ \\
Scenario 2 & $\theta=0.3, \rho=2000, \alpha=0.5, \gamma=0.08, \beta_{i} \in[0.5,2] \longrightarrow s=0, \rho=0, \alpha=0, \gamma=0, \beta_{i} \in[1.5,3]$ \\
Scenario 3 & $\gamma=0.08 \longrightarrow \gamma=0$ \\
Scenario 4 & $\theta=0.3, \rho=2000, \alpha=0.5 \longrightarrow s=0, \rho=0, \alpha=0$ \\
\hline
\end{tabular}

where $\varepsilon_{i}$ is a parameter $\varepsilon_{i}>1$ and $p_{s j}$ is the subsidy for the green product of manufacturer $j$ whose green degree is higher than the specified standard which is shown in Equation (3), and $p_{e}$ is the consumer expected price of the product.
In the utility function, we assume that the quality of the product consists of green quality and the other quality. The green quality is defined as the overall impact of the multiple green attributes of a manufacturer's product, which is 
TABLE 3: The definitions of indicators.

\begin{tabular}{|c|c|}
\hline Indicators & Definitions \\
\hline Number of LGDM in the market & $\begin{array}{l}\text { Number of manufacturers whose product green degree is lower than government enter } \\
\text { standard } g_{l}\end{array}$ \\
\hline Number of MGDM in the market & Number of manufacturers whose product green degree is between $g_{l}$ and $g_{h}$ \\
\hline Number of HGDM in the market & Number of manufacturers whose product green degree is larger than $g_{h}$ \\
\hline $\begin{array}{l}\text { Average product green degree of all } \\
\text { manufacturers }\end{array}$ & $\frac{1}{N} \sum_{N} g_{j}$ \\
\hline Market share of LGDM & $\sum_{\text {LGDM }} \sum_{i}^{N} s_{i j}$ \\
\hline Market share of MGDM & $\sum_{M G D M} \sum_{i}^{N} s_{i j}$ \\
\hline Market share of HGDM & $\sum_{\mathrm{HGDM}} \sum_{i}^{N} s_{i j}$ \\
\hline $\begin{array}{l}\text { Average product other quality of } \\
\text { manufacturers }\end{array}$ & $\frac{1}{N} \sum_{N} q_{j}$ \\
\hline Average profit of manufacturers & $\frac{1}{N} \sum_{N} \pi_{j}$ \\
\hline
\end{tabular}

supposed to represent by green degree $g_{j}$. The other quality refers to the qualities in other aspects except for green degree which is denoted by $q_{j}$. According to the outlier avoidance consumer psychological theory [62], when a consumer chooses a manufacturer's product, the nearer the quality of a manufacturer's product is to the quality expected by the consumer, the more sensitive the consumer is to the quality of the product. Therefore, the consumer's sensitivity to green degree and the other quality can be, respectively, expressed as follows:

$$
\begin{gathered}
G_{i j}=\delta_{i}\left|g_{j}-g_{e}\right|, \\
Q_{i j}=\tau_{i}\left|q_{j}-q_{e}\right|,
\end{gathered}
$$

where $\delta_{i}$ is a parameter and $0<\delta_{i}<1, g_{e}$ denotes the costumer agent $i$ 's expected green degree to the $j$-th manufacturer's product, $\delta_{i}$ is a parameter and $0<\tau_{i}<1$, and $q_{e}$ is the customer agent $i$ 's expected other quality for the $j$-th manufacturer's product. According to the studies of $[11,12$, 63], $g_{e}$ and $q_{e}$ are positively correlated with consumers purchasing power, that is, the higher the consumers' purchasing power status is, the more attention they attach to the quality of products. Therefore, they can be defined as follows:

$$
\begin{aligned}
& g_{e}=a_{1} \times k_{i}+b_{1}+\varphi_{1 i}, \\
& q_{e}=a_{2} \times k_{i}+b_{2}+\varphi_{2 i},
\end{aligned}
$$

where $k_{i}$ is the purchasing power of consumer $i, a_{1}\left(a_{1}>0\right)$ is the regression coefficient between the expected green degree of the consumer and his/her purchasing power, $b_{1}$ represents the consumer's fixed expectation of product green degree when his/her purchasing power is 0 , and $\varphi_{1 i}$ is a random number sampled from the uniform distribution, which indicates the random influence of other factors on the expected green degree of consumers. Similarly, $a_{2}\left(a_{1}>0\right)$ denotes the regression coefficient between the expected other quality of the consumer and his/her purchasing power, $b_{2}$ is the consumer's fixed expectation of the product when his/her purchasing power is 0 , and $\varphi_{2 i}$ is a random number drawn from the uniform distribution denoting the random influence of other factors on expected other quality of consumers. In order to obtain the value of $a_{1}, a_{2}, b_{1}, b_{2}$, we have made an investigation and got the value of them by two linear regressions $\left(R_{1}=0.31\right.$ and $\left.R_{2}=0.29\right)$.

Furthermore, we assume that consumers can estimate their expected price based on their expectations of green degrees and other qualities of products. Therefore, $p_{e}$ in Equation (5) can be as shown in Equation (8), where $a_{3}$ is the cost coefficient of the expected green degree for consumers, $a_{4}$ denotes consumers' cost coefficient of the expected other quality, and $\varphi_{3 i}$ is a random number sampled from the uniform distribution that represents the variety of a consumer's expect price of a product.

$$
p_{e}=a_{3} \times g_{e}+a_{4} \times q_{e}+\varphi_{3 i}
$$

The next parameter of the utility function is about the consumer agent sensitivity to the "WOM" effect and herd effect [64]. When a consumer $i$ keeps in touch with his/her friend about the product in the social network, his/her utility of the product will be modified correspondingly. The changing rules of utility $\mathrm{FE}_{i j}$ for consumer are defined as follows:

$$
\mathrm{FE}_{i j}=f_{i} \times \mathrm{sf}_{i j},
$$




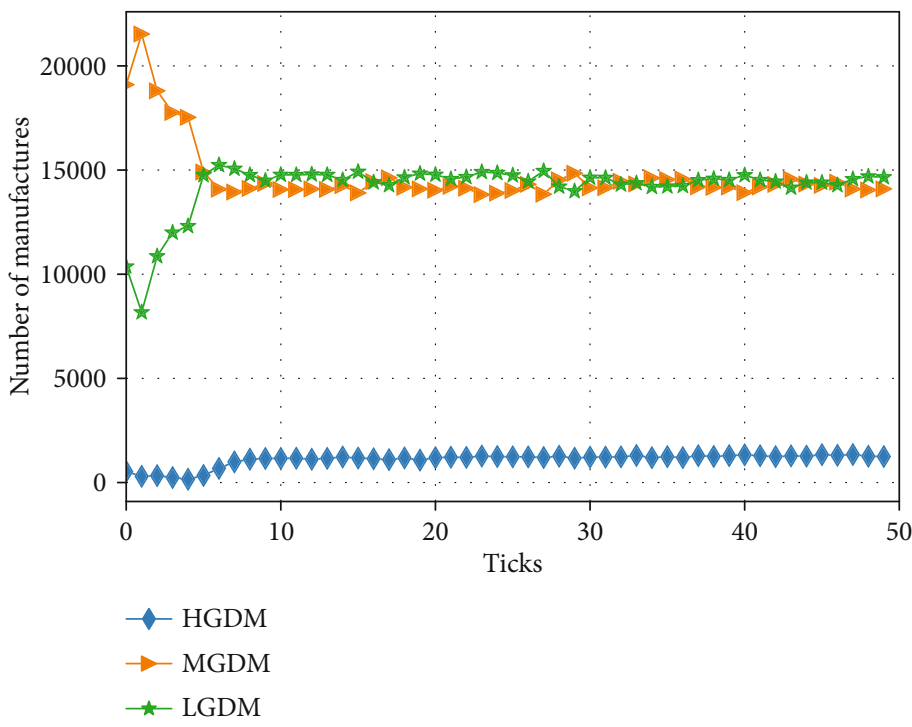

(a) Scenario 1

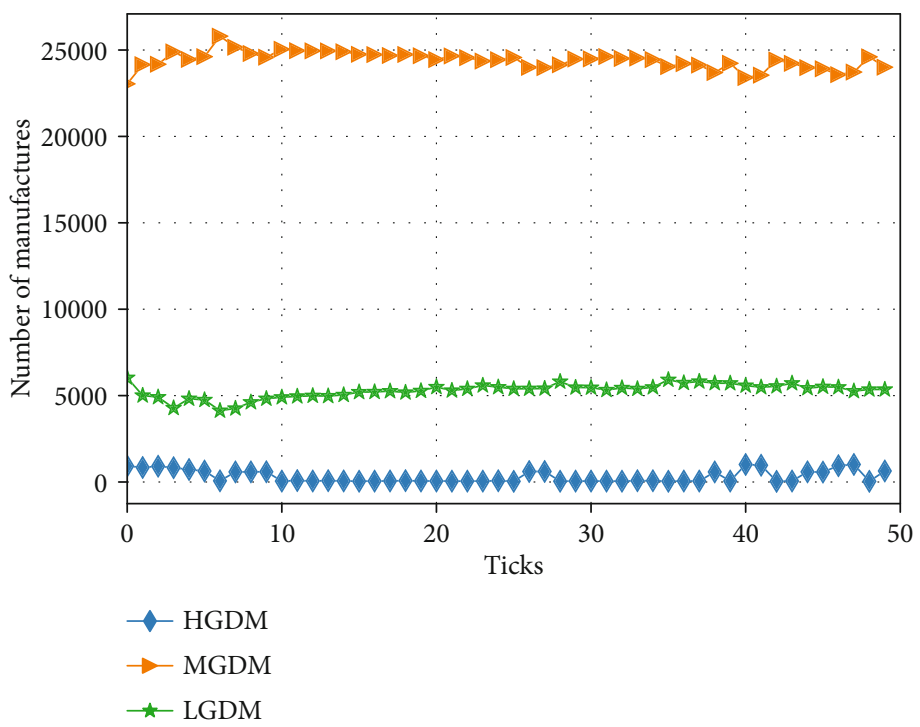

(b) Scenario 2

Figure 2: Continued. 


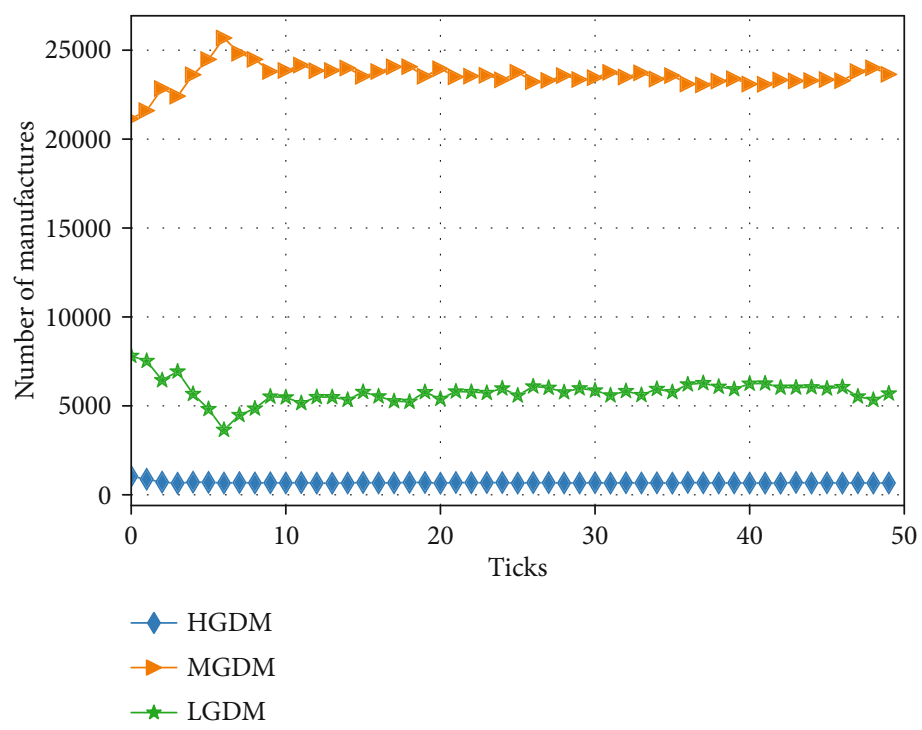

(c) Scenario 3

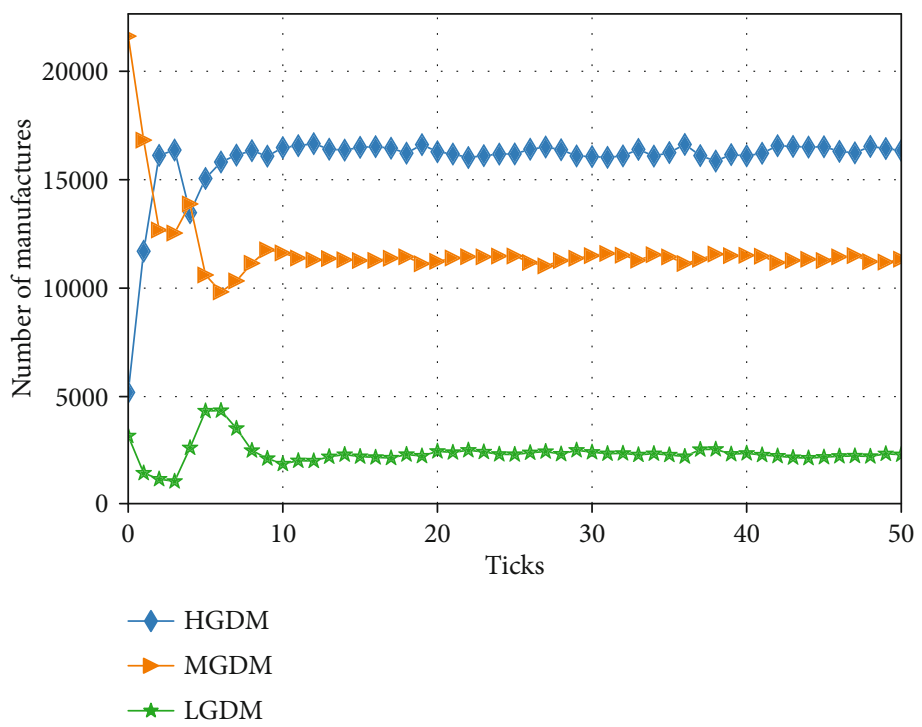

(d) Scenario 4

FIGURE 2: Evolutions of the three kinds of manufacturers' numbers under four scenarios.

where $f_{i}$ is the sensitivity parameter of consumer $i$ to his friends' influence, and we supposed that $f_{i}$ follows an uniform distribution on $(0,1.5)$. The smaller the value of $f_{i}$ is, the less possible consumer $i$ is to be affected by others around him/her and vice versa. $\mathrm{sf}_{j}$ stands for the impact of other consumers in the social network, which is got by consumer $i$; it is measured as the average utility of manufacturer $j$ 's product for his/her neighbors who have purchased the product $j$ in the social network. We set parameter $\mathrm{sl}_{l j}=1$ denotes that a consumer $i$ 's neighbor 1 buys a product of manufacturer $j$ and $\mathrm{sl}_{l j}=0$ stands for a neighbor who does not purchase the product, and the number of consumer $i$ 's friends who have purchased manufacturer $j$ 's product in the social network can be calculated by $\sum_{\text {neighbors }} \mathrm{sl}_{l j}$. The coefficient $\mathrm{sf}_{i j}$ is shown in Equation (10).

$$
\mathrm{sf}_{i j}=\frac{\sum_{\text {neighbors }} U_{l j} \times \mathrm{sl}_{l j}}{\sum_{\text {neighbors }} \mathrm{sl}_{j}},
$$

where $U_{l j}$ is the neighbor l's utility of manufacturer $j$ 's products.

Furthermore, it is considered that consumers do not only compare the total utility of the product to decide whether to buy or not but to have irrational behavior. A common way to describe consumers' bounded rationality is to use a logit model [65] in which the bigger utility value means that consumers have a higher probability of purchasing the product, while the less utility value indicates lower purchasing 


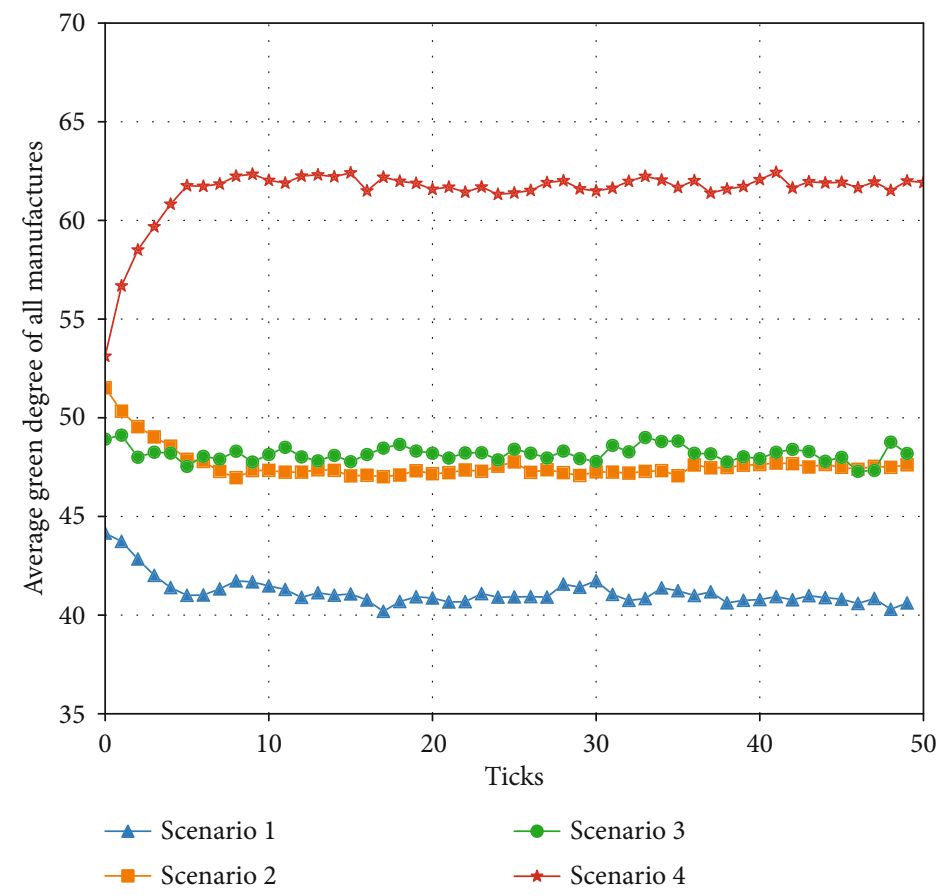

FIGURE 3: Evolutions of average products' green degree of the three types of manufacturers.

probability. According to the research of Xuanming [66], the probability of consumer $i$ with bound irrationality buying a product $j$ is shown as follows:

$$
\operatorname{Prob}_{i j}=\frac{e^{U_{i j}}}{1+e^{U_{i j}}},
$$

where $U_{i j}$ is the utility that consumer $i$ perceives a product of manufacturer $j$.

According to Equations (10) and (11), the order in which consumer $i$ enters the market will affect the probability of purchasing a product. We assume that the consumer with the maximum degree, which means this consumer has the most friends in the network, firstly makes the decision. The rest of consumers randomly do the decision-making of purchasing products.

3.4. The Manufacturer Agents. We suppose that there are $N$ manufacturers with different locations in a specific industry. And the manufacturer processes raw materials and sells its products to consumers. It is supposed that products from manufacturers have differences in price, green degree, and the other quality. And the rest attributes are all the same. Consequently, manufacturers will compete on the price, green degrees, and other quality of their products.

It is well known that when a manufacturer produces a product that is greener or of higher other quality, the production process should be more complex and more demanding in terms of technology or materials, so the manufacturer will inevitably have to invest additional costs for these. We divide the cost of per unit product into three parts: the first part is the fixed unit cost; the second part is the extra margin cost caused by green degree, and the third is the additional margin cost caused by the other quality. Then, the cost function of manufacturer $j$ is defined as follows:

$$
C_{j}=c_{j}+\frac{1}{2} u_{j} g_{j}^{2}+\frac{1}{2} z_{j} q_{j}^{2}
$$

where $c_{j}$ is the regular unit cost and follows a uniform distribution for the manufacturer $j$ 's product, $u_{j}$ represents the cost coefficient associating with the green degree $g_{j}$, and $z_{j}$ stands for the cost factor related to the other quality $q_{j}$. According to previous studies of $([3,30]), 1 / 2 u_{j} g_{j}^{2}$ and $1 / 2$ $z_{j} q_{j}^{2}$ are quadratic function of $g_{j}$ and $q_{j}$, because it is well known that environmental performance and quality improvement have an increasing marginal cost.

We assume that the manufacturer employs the cost-plus pricing method to decide the price of their products. Hence, the product's price of the $j$-th manufacturer is given as $p_{j}=$ $C_{j}\left(1+e_{j}\right)$, where $e_{j}$ symbolizes the profit margins. As a result, the expression of $p_{j}$ is shown as follows:

$$
p_{j}=\left(C_{j}+\frac{1}{2} u_{j} g_{j}^{2}+\frac{1}{2} z_{j} q_{j}^{2}\right)\left(1+e_{j}\right)
$$

In addition, if we set parameter $s_{i j}=1$, it denotes that a consumer $i$ buys a product of manufacturer $j$, and $s_{i j}=0$ stands for a consumer $i$ who does not purchase the product. Then, the sale amount of manufacturer $j$ in a simulation cycle can be calculated by $\sum_{i=1}^{N} s_{i j}$. And the profit function of 


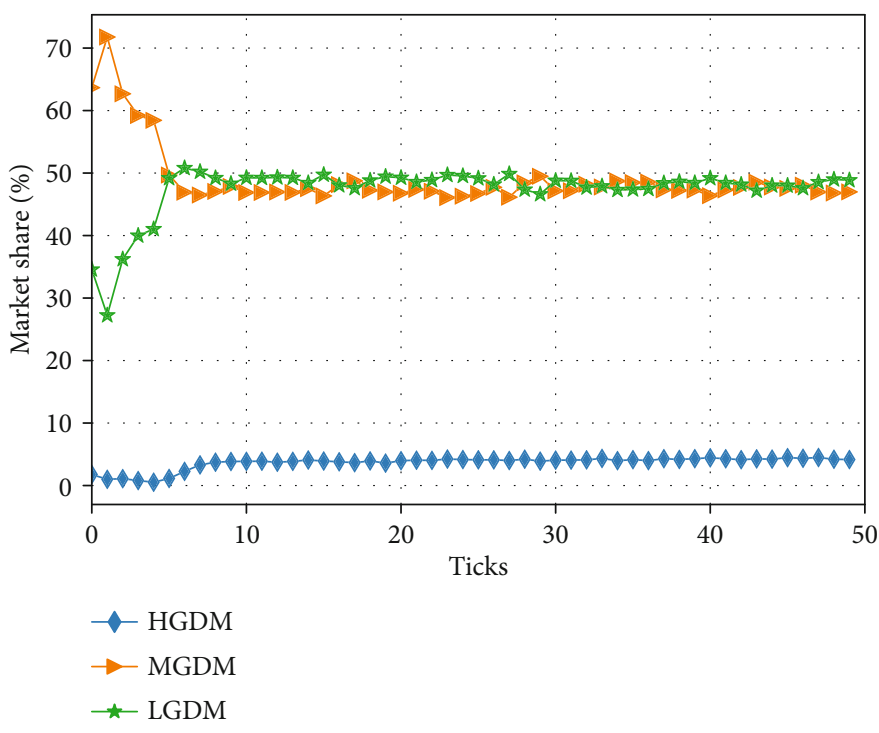

(a) Scenario 1

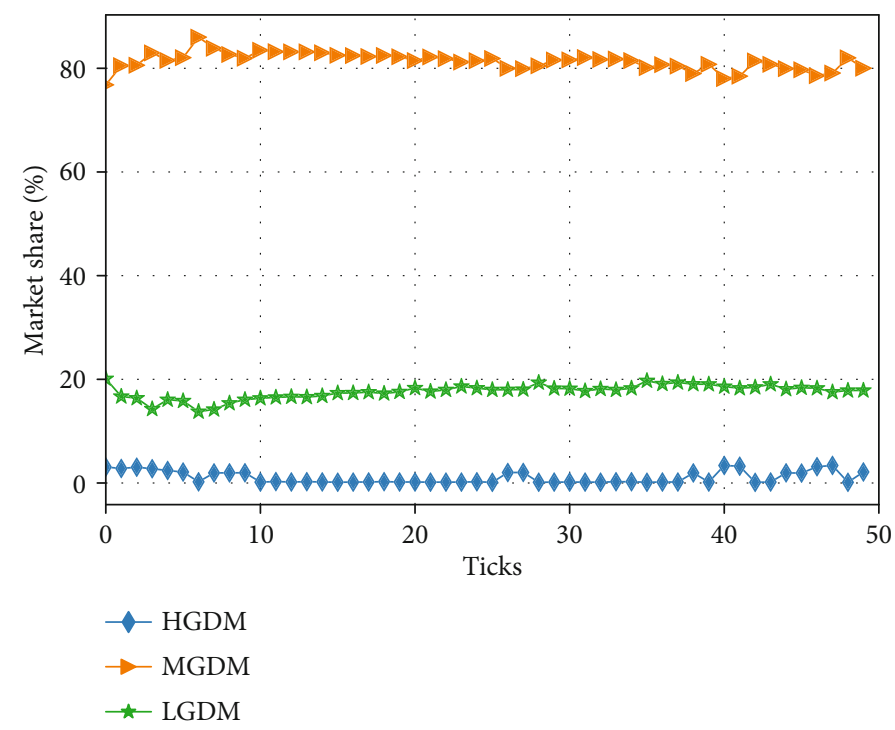

(b) Scenario 2

FIgure 4: Continued. 


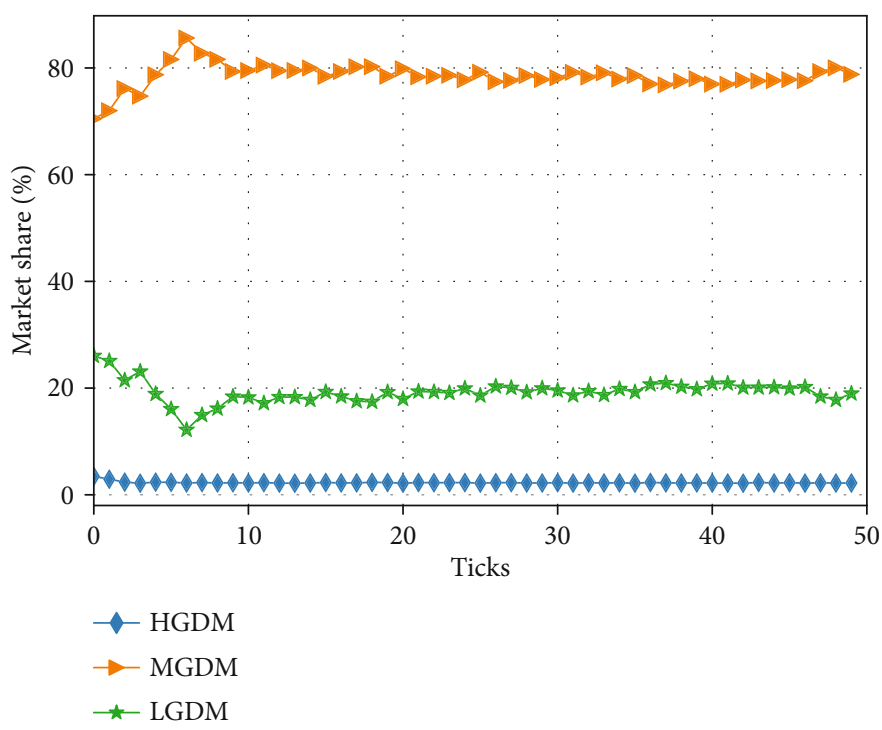

(c) Scenario 3

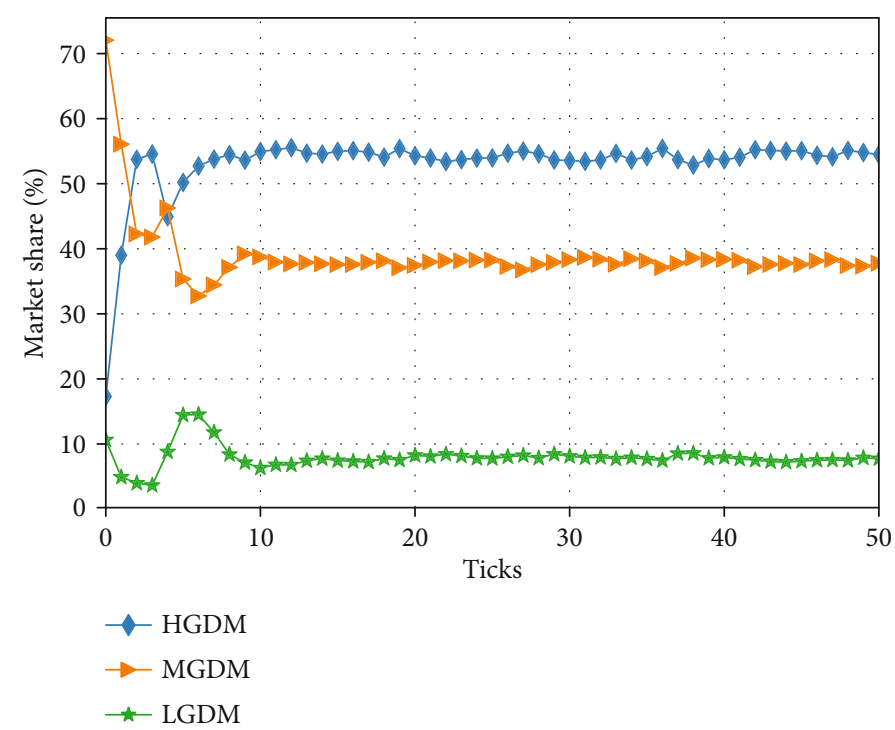

(d) Scenario 4

FIgURE 4: Evolutions of the market share of three types of manufacturers in four scenarios.

manufacturer $j$ is shown as follows:

$$
\pi_{j}=\left(p_{j}-C_{j}\right) \sum_{i=1}^{M} s_{i j}
$$

Moreover, if a manufacturer's product green degree is higher than the government's stipulated standards $g_{h}$, it will apply for subsidies from the government. When a manufacture's product's green degree is lower than the $g_{l}$, it could be punished by the government. Based on Equations (1) and (2), the profit function of manufacturer $j$ can be shown as follows:

$$
\pi_{j}=\left(p_{j}-C_{j}\right) \sum_{i=1}^{M} s_{i j}+\mathrm{SF}_{j} \sum_{i=1}^{M} s_{i j}-\mathrm{PF}_{j} .
$$

Each manufacturer in the market has intelligence and adaptability, and they are learning from each other in the process of competition, especially the manufacturer with the highest profits in their neighborhood. It is supposed that manufacturers do not have technical barriers and production capacity constraints. So, the manufacturer can modify the green degree and the other quality according to their profits without additional costs of production adjustment.

The manufacturer $j$ decides the successive green degree $\left(g_{j}(t+1)\right)$ and the other quality $\left(q_{j}(t+1)\right)$ of its products according to its current product green degree $\left(g_{j}(t)\right)$ and the other quality $\left(q_{j}(t)\right)$, the historical product green degree $\left(g_{j \text { best }}\right)$ and the other quality $\left(q_{j \text { best }}\right)$ which led to the best profit in its history, and the current product green degree and the other quality of its best neighbor who has the maximum profits among all its neighbors within a specific range. 


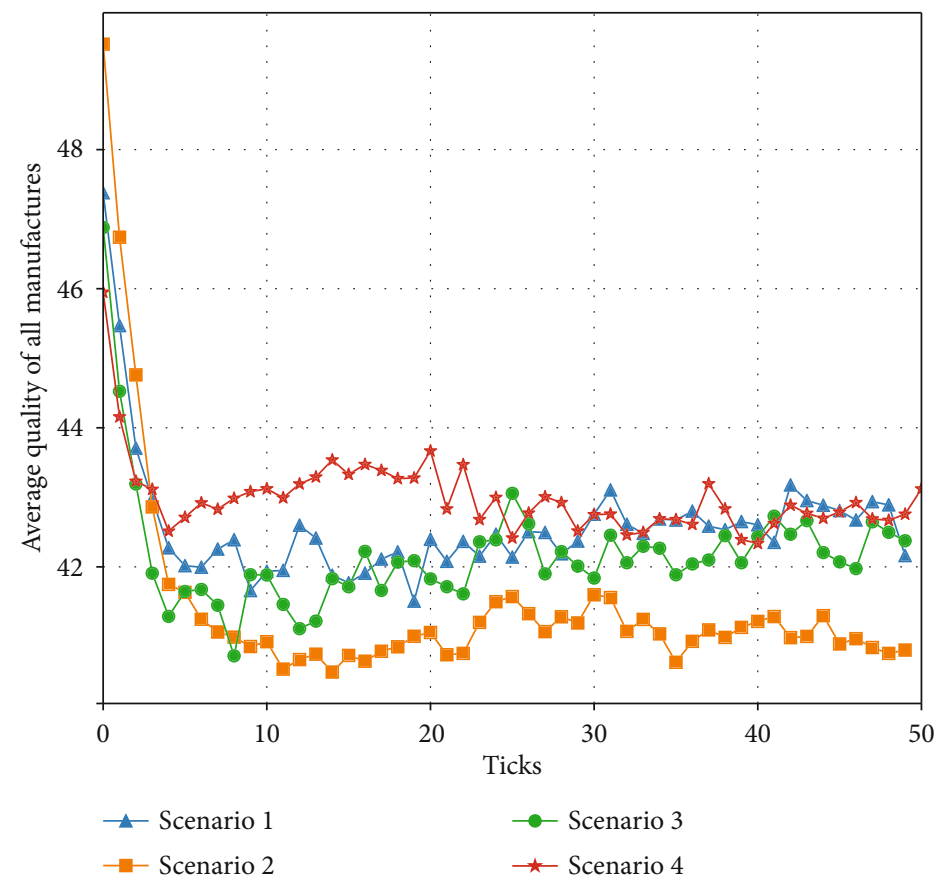

FIGURE 5: Evolutions of average products' other quality of the three types of manufacturers.

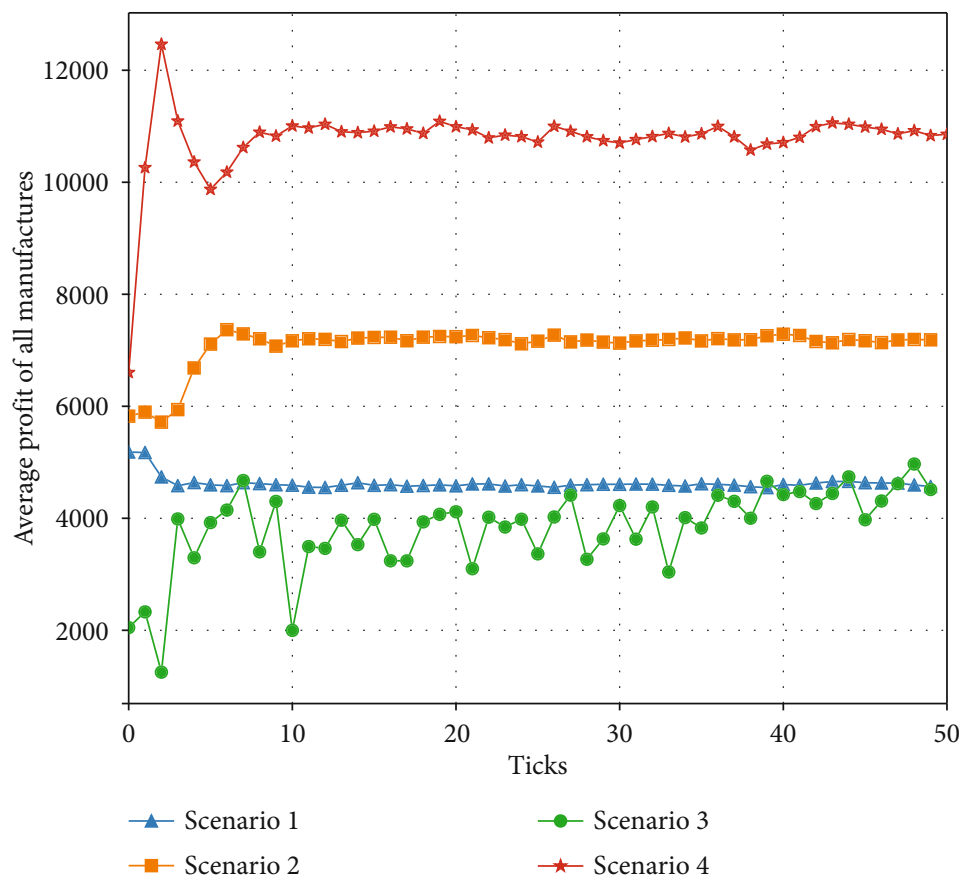

Figure 6: Evolutions of the average profits of the three types of manufacturers.

There are five steps for a manufacturers' updating its green degree and the other quality. The five steps are described as follows:

Step 1. There are $M$ manufacturers in a 2-D space. And generate their positions $X$ and $Y$, the initial green degree $g_{j}$, and other quality $q_{j}$ at random.
Step 2. Calculating manufacturer $j$ 's profit $\pi_{j}(t)$ according to Equation (15).

Step 3. When the current manufacture's profits $\pi_{j}(t)$ is higher than its historical $\pi_{j \text { best }}$, then we replace the values of $\pi_{j \text { best }}$, $\mathrm{g}_{\text {jbest }}$, and $q_{j \text { best }}$ with the values of $\pi_{j}(t), g_{j}(t)$. and $q_{j}(t)$. 
Step 4. Setting a distance threshold $d$ and finding out all the neighbors within the distance $d$. The best neighbor who has the maximum profit among all its neighbors is identified, and its profit, green degree, and other quality are defined as $\pi_{\text {best }}, g_{\text {best }}$, and $q_{\text {best }}$. If $\pi_{\text {best }}>\pi_{\text {best }}$, then the manufacturer will learn the best neighbor's strategies in green degree and other quality with a certain probability. In order to represent the noise and irrational behavior of the learning process, we use the Fermi function [67] to calculate the learning probability, which is expressed in Equation (16)

$$
\operatorname{Prob}(j \stackrel{\text { learning }}{\longrightarrow} \text { best neighbor })=\frac{1}{1+\exp \left[\left(\pi_{\text {best }}-\pi_{\text {jbest }}\right) / \omega\right]} \text {. }
$$

where $\omega$ denotes the noise in the updating process of strategy and $\omega>0$. A random variable $v(v \in[0,1])$ is generated by computer to determine how the manufacturer ultimately changes its green degree and other quality. The update rules are shown in Equations (17) and (18).

$g_{j}(t+1)= \begin{cases}g_{j}(t)+\text { lea }_{j}\left(g_{\text {best }}-g_{j \text { best }}\right) & \text { if } v<\text { Prob, } g_{\text {best }}>g_{j \text { best }}, \\ g_{j}(t)-\text { lea }_{j}\left(g_{j \text { best }}-g_{\text {best }}\right) & \text { if } v<\text { Prob, } g_{\text {best }}<g_{j \text { best }}, \\ g_{j}(t) & \text { if } v>\text { Prob, }\end{cases}$

$p_{j}(t+1)= \begin{cases}p_{j}(t)+\text { lea } 2_{j}\left(p_{\text {best }}-p_{j \text { best }}\right) & \text { if } v<\text { Prob, } \mathrm{p}_{\text {best }}>p_{j \text { best }}, \\ p_{j}(t)-\mathrm{lea} 2_{j}\left(p_{j \text { best }}-p_{\text {best }}\right) & \text { if } v<\text { Prob, } \mathrm{p}_{\text {best }}<p_{j \text { best }} \\ p_{j}(t) & \text { if } v>\text { Prob }\end{cases}$

where lea $1_{j}\left(0<\right.$ lea $\left.1_{j} \leq 1\right)$ and lea $2_{j}\left(0<\right.$ lea $\left.2_{j} \leq 1\right)$ are the learning ability coefficient of manufacturer $j$.

If $\pi_{\text {jbest }}$ is larger than $\pi_{j}(t)$, we update $g_{j}(t+1)$ and $q_{j}(t$ +1 ) as Equations (19) and (20).

$$
\begin{gathered}
g_{j}(t+1)=g_{j \text { best}}, \\
q_{j}(t+1)=q_{j \text { best }},
\end{gathered}
$$

Step 5. Return to step 2, when every manufacturer has been updated.

\section{Simulation Scenario Design}

We suppose that there are 40 manufacturer agents and 30,000 consumer agents in a particular market. To obtain the simulation results, we set the used parameters' initial values that are shown in Table 1.

On the basis of additional guidance and regulation strategies of the government, four different scenarios are constructed. Scenario 1 assumes that the government does not interfere with manufacturers' production and consumer's purchasing price. Scenario 2 supposes that consumer envi- ronmental awareness is increased. Scenario 3 supposes that the government subsidizes the costs of manufacturers whose products are greener than the subsidized standard and penalizes the manufacturers whose products are lower than the market entry standard in the form of sampling. Scenario 4 assumes that the government subsidizes the price of products above the specified standard. The four scenarios' parameters' changes are shown in Tables 2.

To facilitate the analysis, we classify manufacturers into three categories: those whose products' green degree is lower than government enter standard $g_{l}$ (we call them low green degree manufacturer (LGDM)), those whose product green degree is between $g_{l}$ and $g_{h}$ (we call them medium green degree manufacturer (MGDM)), and those whose products are greener than subsidy standard $g_{h}$ (we call them high green degree manufacturer (HGDM)). Several indicators are designed to discover the relationships among government regulation, consumers' product choice and manufacturers' production decisions, and the whole market characteristics and evolutionary trend. The numbers of LGDM, MGDM, and HGDM, the average green degree of manufacture's product, the market share, the average other quality, and profits of three types of manufacturers are analyzed in the four scenarios. The details of the indicators are present in Table 3.

We executed the ABM model in Python 3.7.1 and carried out the experiments in four scenarios. Then, we compute the value of the indicators and analyze them in the next section.

\section{Result Analysis}

5.1. Numbers of LGDM, MGDM, and HGDM. The quantity change of three kinds of manufacturers' numbers can directly show the modifications of manufacturers' production behavior. The numbers of LGDM, MGDM, and HGDM in the four scenarios are shown in Figure 2. The number of MGDM manufacturers increases to a stable level, and the number of LGDM and HGDM both gradually decrease to a specific value in scenarios 1,2 , and 3 , while in scenario 4 , the number of MGDM manufacturers first rises and then reduces to stable status, and the number of HGDM manufacturers gradually increases to the stable level, and the number of LGDM manufacturers gradually decreases to a stable value. Comparing the four scenarios, the number of HGDM manufacturers in different scenarios follows the descending order of scenario 4 , scenario 2 , scenario 3 , and scenario 1 ; the number of MGDM follows the order of scenario 2, scenario 3, scenario 1, and scenario 4; the number of LGDM follows the order of scenario 1, scenario 2, scenario 3, and scenario 4 .

In analyzing the number of LGDM, MGDM, and HGDM, we get two observations. Firstly, manufacturers' green production behavior needs government guidance and regulation, and appropriate policies and measures have effective impacts on the manufacturers' decisions of green degree. Secondly, the government's green cost subsidy and low green degree punishment and increasing consumer awareness of the environment could increase the number of MGDN, but they could not have a significant impact on HGDM 
manufacturer, while the government's product price subsidy has an essential impact on the number of HGDM manufacturers.

In Figure 3, we describe the evolution of the average green degree of all manufacturers in four scenarios. It can be seen from Figure 3 that the average green degree of all manufacturers is the highest in scenario 4 , and there is no significant difference between scenario 2 and scenario 3 . Thus, price subsidies are the most effective means to affect the green degree of the products; compared to green cost subsidies to manufacturers, the government takes various publicity means to improve the environmental awareness of consumers are also an effective way to increase the green degree of manufacturers' products in the whole market.

5.2. Market Share of Three Kinds of Manufacturers. Consumers are the focus of market competition. Consumers' preferences are heterogeneous (this study shows the heterogeneity of consumer price preference, environmental awareness, and quality preference). Some manufacturers win a large number of consumers and occupy a high market share by positioning their product appropriately on price, green degree, and the other quality. Figure 4 shows the market share of three types of manufacturers in four scenarios. In scenario 1, the market share of MGDM manufacturers first increases and then decreases and stabilizes at about $48 \%$. The market share of LGDM first falls and then rises and remains stable at about $48 \%$. Without intervention, the market share is occupied by LGDM and MGDM manufacturers, while HGDM manufacturers have a small market share (about 3\%). The market share distribution of scenario 2 and scenario 3 is similar. MGDM manufacturers occupy about $80 \%$ of the market share, while LGDM manufacturers have about $17 \%$ of the market share, and HGDM firms have about $3 \%$ of the market share. In scenario 4 , the market share of HGDM manufacturer increases first and then decreases and gradually stabilizes at about 54\%. The market share of MGDM manufacturers decreases from $72 \%$ to $38 \%$. The market share of LGDM manufacturers fall first, then increased and then decreased, and finally stabilized at about $8 \%$.

Through the above analysis, it can be concluded that the distribution of the market share of the three types of manufacturers is different with different guidance and regulation strategies of the government. When consumers' environmental awareness is enhanced, and the government punishes LGDM enterprises, gives green cost subsidies to manufacturers with a high green degree, most of the market share is obtained by MGDM manufacturers. When the government subsidizes the price of products, the market share is occupied by HGDM manufacture.

5.3. Average Other Quality of Manufacturers. In Figure 5, we depict the evolutionary trend of the average other quality of the manufacturer's products in the four scenarios. As can be seen in Figure 5, as competition in the market proceeds, the average other quality of the products in the market shows a tendency first to decline and then fluctuate within a small range. On the whole, the average quality of the products in scenario 4 and scenario 1 is highest, followed by scenario 3 and the lowest in scenario 2.

Therefore, it can be concluded that manufacturers would learn to modify the other quality of their products to increase the profits in a competitive market. Second, there may be a "Crowding Out Effect" on the other qualities of manufacturers' products when they focus on the green degree of its products. This "Crowding Out Effect" is significant when consumers are more environmentally conscious in the four scenarios. When the government subsidizes the green cost of a manufacturer whose green degree is larger than a stander and punishes the manufacturer whose green degree is smaller than the environmental access standards, it is less significant; subsidizing the price of the product basically does not have this effect.

5.4. Average Profit of Manufacturers. The three types of manufacturers' average profits of the four scenarios are presented in Figure 6, and the evolution of it shows different characteristics. In scenario 1, the average profits of the manufacturers fluctuate in a small range. In scenario 2 , the average profits of the manufacturer are bigger than that of scenario 1, and it rises initially and gradually stabilizes at a stable level. This is due to the enhancement of consumers' environmental awareness, and consumers with high environmental preferences tend to buy high green products and pay higher prices for them. In scenario 3, the average profit of the manufacturers fluctuates in a wide range and shows an upward trend. The main reason for this phenomenon is when manufacturers with a low green degree are investigated and punished, and they bear high fines, which affects the average profit of manufacturers in the market. The punished manufacturers improve the product green degrees to avoid the fine. Besides, government subsidies also stimulate manufacturer to enhance the green degree of products, and because the manufacturer adopts the cost-plus pricing method to decide the product's price, the higher the green degree of the product, the higher the cost, and the larger the profit of a product, so the average profit of the manufacturers is gradually increasing. In scenario 4 , the average profits of the manufacturer are always kept at a high level and progressively stabilized after a wide fluctuation. This duo to the market is occupied by the manufacturers of HGDM according to Figure 4, and the manufacturers with the high green degree products have gained decent profits.

The above analysis indicates that government green cost subsidies and punishment of low green degree manufacturers can produce good results, but they will affect the stability of manufacturers' profit and the market. The government's price subsidies and increasing consumers' environmental awareness can improve the average profit level of the manufacturers while maintaining market stability.

\section{Conclusions}

It is crucial to clear up the evolving trends of product green degree in the market and its influence upon the manufacturers' competitive performance in different scenarios. To help the government and manufacturers make reasonable 
decisions, we construct an agent-based model to study the green production behavior of manufacture, which considers the interactions of government, consumer, and government.

The results of the simulations provide three conclusions, which could be summarized as follows: firstly, the green product production behavior of the manufacturer needs the guidance and regulation of the government. Secondly, product price subsidies are the most effective means to affect the green degree of the products; comparing with giving green cost subsidies to manufacturers, the government employs various publicity means to improve the environmental awareness of consumers is also an effective way to improve the green degree of manufacturers' products. Thirdly, there is a "Crowding Out Effect" on the other qualities of manufacturers' products when manufacturers focus on the green degree of their products.

In light of the above findings, we suggest the as following insights for the government when developing policies about facilitating the production of green products. Firstly, the government can improve the environmental awareness of consumers and cultivate their green consumption habits by enhancing environmental protection publicity or subsidizing green products. In this way, firms have an incentive to produce green products, because market demand preference will stimulate manufacturers to make green production and increase their market share. Secondly, when the government subsidizes green products, it can choose to subsidize the price of products to consumers as a more efficient way than subsidizing the cost of manufacturers. In addition, the government should also pay active attention to other qualities of green products. When the government conducts green product subsidies, it will cause "Crowding Out Effect" on other qualities, which will cause a loss of consumer welfare.

In addition, to facilitate the study, this work only considers the government and consumers who have a more significant effect on the manufacturers' product green degree decisions. In reality, investors and nongovernmental environmental organizations will also affect the green product production behavior of enterprises. In further research, we can add the above subjects to the model, enrich, and improve the model, so that it can reflect the complex reality.

\section{Data Availability}

The simulation model and experimental data used to support the findings of this study are available from the corresponding author upon request.

\section{Conflicts of Interest}

The authors declare that they have no conflicts of interest.

\section{Acknowledgments}

This work is supported by the National Social Science Foundation of China, grant number 20BGL047.

\section{References}

[1] V. Albino, A. Balice, and R. M. Dangelico, "Environmental strategies and green product development: an overview on sustainability-driven companies," Business Strategy and the Environment, vol. 18, no. 2, pp. 83-96, 2009.

[2] J. Gao, Z. Xiao, H. Wei, and G. Zhou, "Active or passive? Sustainable manufacturing in the direct-channel green supply chain: a perspective of two types of green product designs," Transportation Research Part D: Transport and Environment, vol. 65, pp. 332-354, 2018.

[3] Q. Meng, M. Li, Z. Li, and J. Zhu, "How different government subsidy objects impact on green supply chain decision considering consumer group complexity," Mathematical Problems in Engineering, vol. 2020, Article ID 5387867, 12 pages, 2020.

[4] R. M. Dangelico, "What drives green product development and how do different antecedents affect market performance? A survey of Italian companies with eco-labels," Business Strategy and the Environment, vol. 26, no. 8, pp. 1144-1161, 2017.

[5] S. Du, W. Tang, J. Zhao, and T. Nie, "Sell to whom? Firm's green production in competition facing market segmentation," Annals of Operations Research, vol. 270, no. 1-2, pp. 125-154, 2018.

[6] S. Du, J. Zhu, H. Jiao, and W. Ye, "Game-theoretical analysis for supply chain with consumer preference to low carbon," International Journal of Production Research, vol. 53, no. 12, pp. 3753-3768, 2015.

[7] P. Liu and S.-p. Yi, "Pricing policies of green supply chain considering targeted advertising and product green degree in the big data environment," Journal of Cleaner Production, vol. 164, pp. 1614-1622, 2017.

[8] M. A. Ülkü and J. Hsuan, "Towards sustainable consumption and production: competitive pricing of modular products for green consumers," Journal of Cleaner Production, vol. 142, pp. 4230-4242, 2017.

[9] Y. Yu, X. Han, and G. Hu, "Optimal production for manufacturers considering consumer environmental awareness and green subsidies," International Journal of Production Economics, vol. 182, pp. 397-408, 2016.

[10] E. Moser, A. Seidl, and G. Feichtinger, "History-dependence in production-pollution-trade-off models: a multi-stage approach," Annals of Operations Research, vol. 222, no. 1, pp. 457-481, 2014.

[11] Z. Li, H. Zhu, Q. Meng, C. Wu, and J. Du, "Manufacturers' green decision evolution based on multi-agent modeling," Complexity, vol. 2019, Article ID 3512142, 14 pages, 2019.

[12] T. Li, R. Zhang, S. Zhao, and B. Liu, "Low carbon strategy analysis under revenue-sharing and cost-sharing contracts," Journal of Cleaner Production, vol. 212, pp. 1462-1477, 2019.

[13] J. Wang, S. Wang, H. Xue, W. Yu, and J. Li, “Green image and consumers' word-of-mouth intention in the green hotel industry: the moderating effect of Millennials," Journal of Cleaner Production, vol. 181, pp. 426-436, 2018.

[14] E. J. Seo, J.-W. Park, and Y. J. Choi, "The effect of social media usage characteristics on e-WOM, trust, and brand equity: focusing on users of airline social media," Sustainability, vol. 12, no. 4, p. 1691, 2020.

[15] S. Hendershot, "Is green enough to lure clients," Crain's Chicago Business, vol. 32, no. 28, p. 16, 2009.

[16] T. Stucki, M. Woerter, S. Arvanitis, M. Peneder, and C. Rammer, "How different policy instruments affect green 
product innovation: a differentiated perspective," Energy Policy, vol. 114, pp. 245-261, 2018.

[17] Z. Liu, T. D. Anderson, and J. M. Cruz, "Consumer environmental awareness and competition in two-stage supply chains," European Journal of Operational Research, vol. 218, no. 3, pp. 602-613, 2012.

[18] S. Swami and J. Shah, "Channel coordination in green supply chain management," Journal of the Operational Research Society, vol. 64, no. 3, pp. 336-351, 2013.

[19] I. Nouira, Y. Frein, and A. B. Hadj-Alouane, "Optimization of manufacturing systems under environmental considerations for a greenness-dependent demand," International Journal of Production Economics, vol. 150, pp. 188-198, 2014.

[20] A. K. Moser, “Thinking green, buying green? Drivers of proenvironmental purchasing behavior," Journal of Consumer Marketing, vol. 32, no. 3, pp. 167-175, 2015.

[21] Y. J. Chen and J.-B. Sheu, "Non-differentiated green product positioning: roles of uncertainty and rationality," Transportation Research Part E: Logistics and Transportation Review, vol. 103, pp. 248-260, 2017.

[22] Z. Hong, H. Wang, and Y. Yu, "Green product pricing with non-green product reference," Transportation Research Part E: Logistics and Transportation Review, vol. 115, pp. 1-15, 2018.

[23] D. Ghosh and J. Shah, "A comparative analysis of greening policies across supply chain structures," International Journal of Production Economics, vol. 135, no. 2, pp. 568-583, 2012.

[24] G. Xie, "Cooperative strategies for sustainability in a decentralized supply chain with competing suppliers," Journal of Cleaner Production, vol. 113, pp. 807-821, 2016.

[25] D. Yang and T. Xiao, "Pricing and green level decisions of a green supply chain with governmental interventions under fuzzy uncertainties," Journal of Cleaner Production, vol. 149, pp. 1174-1187, 2017.

[26] B. Shen, Y. Cao, and X. Xu, "Product line design and quality differentiation for green and non-green products in a supply chain," International Journal of Production Research, vol. 58, no. 1, pp. 148-164, 2020.

[27] S. Saha, S. Majumder, and I. E. Nielsen, "Is it a strategic move to subsidized consumers instead of the manufacturer?," IEEE access, vol. 7, pp. 169807-169824, 2019.

[28] Y. Fang, X. Wang, and J. Yan, "Green product pricing and order strategies in a supply chain under demand forecasting," Sustainability, vol. 12, no. 2, p. 713, 2020.

[29] C. Xin, X. Chen, H. Chen, S. Chen, and M. Zhang, "Green product supply chain coordination under demand uncertainty," IEEE Access, vol. 8, pp. 25877-25891, 2020.

[30] S. Zhang, Y. Yu, Q. Zhu, C. M. Qiu, and A. Tian, "Green innovation mode under carbon tax and innovation subsidy: an evolutionary game analysis for portfolio policies," Sustainability, vol. 12, no. 4, p. 1385, 2020.

[31] E. L. Olson, "It's not easy being green: the effects of attribute tradeoffs on green product preference and choice," Journal of the Academy of Marketing Science, vol. 41, no. 2, pp. 171184, 2013.

[32] H.-h. Zhao, Q. Gao, Y.-p. Wu, Y. Wang, and X.-d. Zhu, "What affects green consumer behavior in China? A case study from Qingdao," Journal of Cleaner Production, vol. 63, pp. 143151, 2014.

[33] R. Yadav and G. S. Pathak, "Young consumers' intention towards buying green products in a developing nation: extend- ing the theory of planned behavior," Journal of Cleaner Production, vol. 135, pp. 732-739, 2016.

[34] N. M. Suki, "Green product purchase intention: impact of green brands, attitude, and knowledge," British Food Journal, vol. 118, no. 12, pp. 2893-2910, 2016.

[35] Q. Zhu, Y. Li, Y. Geng, and Y. Qi, "Green food consumption intention, behaviors and influencing factors among Chinese consumers," Food Quality and Preference, vol. 28, no. 1, pp. 279-286, 2013.

[36] S. Yang and D. Zhao, "Do subsidies work better in low-income than in high-income families? Survey on domestic energyefficient and renewable energy equipment purchase in China," Journal of Cleaner Production, vol. 108, pp. 841-851, 2015.

[37] M. Jo and J. Shin, "Market strategy for promoting green consumption: consumer preference and policy implications for laundry detergent," International Journal of Consumer Studies, vol. 41, no. 3, pp. 283-290, 2017.

[38] A. Kowalska-Pyzalska, "An empirical analysis of green electricity adoption among residential consumers in Poland," Sustainability, vol. 10, no. 7, p. 2281, 2018.

[39] H. Lin, M. Wang, W. Chen, and G. Conzelmann, "Incorporating social impact on new product adoption in choice modeling: a case study in green vehicles," Transportation Research Part D: Transport and Environment, vol. 32, pp. 421-434, 2014.

[40] D. McCoy and S. Lyons, "Consumer preferences and the influence of networks in electric vehicle diffusion: an agent-based microsimulation in Ireland," Energy Research \& Social Science, vol. 3, pp. 89-101, 2014.

[41] A. Khare, "Antecedents to green buying behaviour: a study on consumers in an emerging economy," Marketing Intelligence \& Planning, vol. 33, no. 3, pp. 309-329, 2015.

[42] C.-C. Chen, C.-W. Chen, and Y.-C. Tung, "Exploring the consumer behavior of intention to purchase green products in belt and road countries: an empirical analysis," Sustainability, vol. 10, no. 3, p. 854, 2018.

[43] M. Porter and C. Van der Linde, "Green and competitive: ending the stalemate," Harvard Business Review, vol. 73, no. 5, pp. 120-134, 1995.

[44] J.-B. Sheu and Y. J. Chen, "Impact of government financial intervention on competition among green supply chains," International Journal of Production Economics, vol. 138, no. 1, pp. 201-213, 2012.

[45] G. van Leeuwen and P. Mohnen, "Revisiting the Porter hypothesis: an empirical analysis of green innovation for the Netherlands," Economics of Innovation and New Technology, vol. 26, no. 1-2, pp. 63-77, 2017.

[46] Y. Wang, X. Chang, Z. Chen, Y. Zhong, and T. Fan, "Impact of subsidy policies on recycling and remanufacturing using system dynamics methodology: a case of auto parts in China," Journal of Cleaner Production, vol. 74, pp. 161-171, 2014.

[47] S. R. Madani and M. Rasti-Barzoki, "Sustainable supply chain management with pricing, greening and governmental tariffs determining strategies: a game-theoretic approach," Computers \& Industrial Engineering, vol. 105, pp. 287-298, 2017.

[48] Z. Huang, G. Liao, and Z. Li, "Loaning scale and government subsidy for promoting green innovation," Technological Forecasting and Social Change, vol. 144, pp. 148-156, 2019.

[49] I. E. Nielsen, S. Majumder, and S. Saha, "Exploring the intervention of intermediary in a green supply chain," Journal of Cleaner Production, vol. 233, pp. 1525-1544, 2019. 
[50] I. E. Nielsen, S. Majumder, S. S. Sana, and S. Saha, "Comparative analysis of government incentives and game structures on single and two-period green supply chain," Journal of Cleaner Production, vol. 235, pp. 1371-1398, 2019.

[51] J. Xu, J. Cao, Y. Wang, X. Shi, and J. Zeng, "Evolutionary game on government regulation and green supply chain decisionmaking," Energies, vol. 13, no. 3, p. 620, 2020.

[52] R. Dominguez and S. Cannella, "Insights on multi-agent systems applications for supply chain management," Sustainability, vol. 12, no. 5, p. 1935, 2020.

[53] M. P. Wellman, "Putting the agent in agent-based modeling," Autonomous Agents and Multi-Agent Systems, vol. 30, no. 6, pp. 1175-1189, 2016.

[54] A. Hafezalkotob, "Competition, cooperation, and coopetition of green supply chains under regulations on energy saving levels," Transportation Research Part E: Logistics and Transportation Review, vol. 97, pp. 228-250, 2017.

[55] C. Luo, M. Leng, J. Huang, and L. Liang, "Supply chain analysis under a price-discount incentive scheme for electric vehicles," European Journal of Operational Research, vol. 235, no. 1, pp. 329-333, 2014.

[56] C. Kiss and M. Bichler, "Identification of influencers - measuring influence in customer networks," Decision Support Systems, vol. 46, no. 1, pp. 233-253, 2008.

[57] Q. Yan, L. Wu, and L. Zheng, "Social network based microblog user behavior analysis," Physica A: Statistical Mechanics and its Applications, vol. 392, no. 7, pp. 1712-1723, 2013.

[58] A.-L. Barabási and E. Bonabeau, "Scale-free networks," Scientific American, vol. 288, no. 5, pp. 60-69, 2003.

[59] T. Zhang and D. Zhang, "Agent-based simulation of consumer purchase decision-making and the decoy effect," Journal of Business Research, vol. 60, no. 8, pp. 912-922, 2007.

[60] S. Čavoški and A. Marković, “Agent-based modelling and simulation in the analysis of customer behaviour on B2C ecommerce sites," Journal of Simulation, vol. 11, no. 4, pp. 335-345, 2017.

[61] B.-D. Kim, R. C. Blattberg, and P. E. Rossi, "Modeling the distribution of price sensitivity and implications for optimal retail pricing," Journal of Business \& Economic Statistics, vol. 13, no. 3, pp. 291-303, 2010.

[62] S. Patel and A. Schlijper, "Models of consumer behaviour," in 49th European Study Group with Industry, Oxford, UK, 2004.

[63] A. Adepetu, S. Keshav, and V. Arya, "An agent-based electric vehicle ecosystem model: San Francisco case study," Transport Policy, vol. 46, pp. 109-122, 2016.

[64] D. Godes and D. Mayzlin, "Using online conversations to study word-of-mouth communication," Marketing Science, vol. 23, no. 4, pp. 545-560, 2004.

[65] D. G. Fiebig, M. P. Keane, J. Louviere, and N. Wasi, "The generalized multinomial logit model: accounting for scale and coefficient heterogeneity," Marketing Science, vol. 29, no. 3, pp. 393-421, 2010.

[66] S. Xuanming, "Bounded rationality in newsvendor models," Manufacturing \& Service Operations Management, vol. 10, no. 4, pp. 566-589, 2008.

[67] G. Szabó and G. Fáth, "Evolutionary games on graphs," Physics Reports, vol. 446, no. 4-6, pp. 97-216, 2007. 